\title{
Hydrogel amendment to sandy soil reduces irrigation frequency and improves the biomass of Agrostis stolonifera
}

\author{
Hillary Agaba $^{1 *}$, Lawrence J. B. Orikiriza ${ }^{2}$, Joseph Obua ${ }^{3}$, John. D. Kabasa ${ }^{4}$, Martin Worbes ${ }^{5}$, \\ Aloys Hüttermann 6 \\ ${ }^{1}$ National Forestry Resources Research Institute, Kampala, Uganda; ${ }^{*}$ Corresponding Author: hiagaba@yahoo.com \\ ${ }^{2}$ Department of Forestry, Biodiversity and Tourism, School of Forestry, Environmental and Geographical Sciences, Makerere Uni- \\ versity, Kampala, Uganda; \\ ${ }^{3}$ Interuniversity Council of East Africa, Kampala, Uganda; \\ ${ }^{4}$ School of Veterinary Medicine Makerere University, Kampala, Uganda; \\ ${ }^{5}$ Department for Crop Sciences, Tropical Agriculture Universität, Göttingen, Germany; \\ ${ }^{6}$ Institute of Forest Botany, University of Goettingen, Goettingen, Germany.
}

Received 8 September 2011; revised 15 October 2011; accepted 26 October 2011.

\begin{abstract}
Soil water potential indicates the water status of the soil and the need for irrigation. The effect of hydrogel amendment to the upper sand soil layer on water infiltration into the lower un-amended sand layer, irrigation frequency, water use efficiency and biomass production of Agrostis stolonifera was investigated. The upper $25 \mathrm{~cm}$ sand layer in three identical buckets was amended at $0.4 \%, 0.2 \%$ and a control (no hydrogel) while the lower $25 \mathrm{~cm}$ sand layer separated from the upper layer by a wire mesh in the same buckets was un-amended. Agrostis stolonifera seeds were sown in each bucket and adequately irrigated using a hand sprayer. Potential meter electrodes were inserted at three random positions in each of the buckets and subsequent irrigations were done when a pressure of 600 bars was recorded in any of the three treatments. Data were collected on irrigation frequency, water content in the lower layer, water use efficiency and biomass production of Agrostis stolonifera. The mean water potential in the lower $25 \mathrm{~cm}$ layer un-amended sand was significantly more negative in the $0.4 \%$ hydrogel than in the control. More water content $(10 \%)$ was recorded in the lower layer under the control bucket than in either the $0.2 \%$ and $0.4 \%$ hydrogel amended buckets. The frequency of irrigation was three-fold in the control compared to the $0.4 \%$ hydrogel amended sand. The hydrogel amended sand significantly increased the shoot and root biomass
\end{abstract}

of Agrostis stolonifera by 2.2 and 4 times respectively compared to the control. The $0.4 \%$ hydrogel amendment in sand increased the water use efficiency of grass eight fold with respect to the control. The hydrogel stimulated development of a dense root network and root aggregation that increased contact of the roots with moisture thus improving water use efficiency of hydrogel amended soil. The results suggest that hydrogels can improve sandy soil properties for plant growth by absorbing and keeping water longer in the soil matrix thus reducing watering frequency.

Keywords: Sand; Water Use Efficiency; Hydrogel; Irrigation; Biomass; Agrostis Stolonifera

\section{INTRODUCTION}

Moisture retention in the soil is fundamental in plantation forest establishment [1-3]. Soil water affects plant growth directly because it influences aeration, temperature, nutrient transport, uptake and transformation [4]. Large pore spaces in sandy soils prevent water retention, make water dry out easily and escalates leaching of precious nutrients past plant roots [1], thus hindering plant growth. There have been claims though, that addition of crosslinked polyacrylamide hydrogels to sandy soils reduces the rate of water percolation while increasing the water availability to plants [5].

The amount of soil water is usually measured in terms of percentage by volume or mass [6] or as soil water potential. Water content does not necessarily imply the 
availability of water to plants, nor does it indicate how the water moves within the soil profile but rather, it is the relative amount of water in soil. Soil water potential, which is the energy required to remove water from the soil, does not show the amount of water present in the root zone [4]. Therefore, soil water content and soil water potential should be considered when planning irrigation and taking measures to improve plant growth [4].

Hydrophilic polymers potentially influence infiltration rates, density, soil structure, compaction, soil texture, aggregate stability, crust hardness [7], and evaporation rates [8]. They increase the plant available water in the soil which prolongs plant survival under water stress $[2,9,10]$. While irrigation is critical in overcoming water stress, the timing (which includes measurement of soil water, estimation of loss by evapo-transpiration, and measurement of plant water status) is important $[4,11$, 12]. The low water holding capacity of sand soil causes rapid infiltration and deep percolation below the root zone. The use of gel-forming hydrophilic polymers (hydrogels) has been tested for some years and found to increase the water holding capacity of sandy soils [13, 14].

High water infiltration in sandy soils has been observed to lead to deep percolation and inefficient fertilizer and water use thus posing a significant problem in arid and semi arid regions [1]. Super Absorbent Polymers (SAPs) can store water in the upper horizons of the soil where plant roots are found. Significant reductions in irrigation requirements of many plants due to an increase in water holding capacity by hydrogel-amended soils have been reported [13]. Soil water potential shows the water status of soil and the need for irrigation. At both high $\left(360 \mathrm{~L} / \mathrm{m}^{2}\right)$ and low $\left(36 \mathrm{~L} / \mathrm{m}^{2}\right)$ irrigation speeds, [2] demonstrated that soil moisture was higher in the upper than lower horizons of soils amended with hydrogels after two weeks. Conventional irrigation usually experiences the problem of losing a significant portion of the water to the aquifer $[15,16]$. As noted above, super absorbent hydrogels increase water storage of soils in the upper horizons of the soil thereby saving water and labor requirements in irrigation due to reduced irrigation frequencies. The overall objective of this study was to examine the effect of hydrogel amendment to the upper sand soil layer on water uptake by that layer, irrigation frequency and water availability for the growth of Agrostis stolonifera, a grass species commonly used in golf courses. The specific objectives were to 1) determine the influence of hydrogel amendment on biomass development of Agrostis stolonifera under water potential controlled irrigation timing and 2) determine the effect of hydrogel amendment to the upper sandy soil layer on water infiltration into the lower un-amended sand layer. The following hypotheses were tested: 1) Hydrogel amendment to sand has no effect on the biomass of Agrostis stolonifera, 2) Hydrogel amendment to the upper sand layer does not reduce water infiltration into the lower un-amended layer and 3) Hydrogel amendment does not affect irrigation frequency and saves no water during growth of Agrostis stolonifera. Agrostis stolonifera (bent grass) was traditionally confined almost entirely to golf greens. Now many homeowners prefer bentgrass lawns because of their beautiful carpet like turf.

\section{MATERIALS AND METHODS}

\subsection{Materials}

The materials used in this experiment were Grass seeds (Agrostis stolonifera) luquasorb hydrogel, three identical plastic buckets measuring 51 and $41.3 \mathrm{~cm}$ top and lower diameters respectively, and $50 \mathrm{~cm}$ in height (Volume 83,595 $\mathrm{cm}^{3}$ ) and a potential meter (DMG 900) for measuring water potential in $\mathrm{cm}$ bars. The sand was obtained from a sand pit in Schoningen in the Solling mountains close to Goettingen. Luquasorb hydrogel manufactured by the BASF SE Chemical Company, Ludwigshafen, Germany was used as the soil amendment at the following concentrations: 0 (as control), $0.2 \%$ and $0.4 \%$. The $0.2 \%$ and $0.4 \%$ hydrogel concentrations were made by mixing 2 and $4 \mathrm{~kg}$ of hydrogel powder respectively with $1000 \mathrm{~kg}$ of soil in a concrete mixer (Mini Concrete Mixer, Model: CM 180 - MZ2; Mixing capacity $180 \mathrm{~L}$ ). The control had no hydrogel added. The amount of hydrogel used and the mixing procedures were according to $[6,17]$

\subsection{Methods}

The experiment was conducted in a glass house set up at a temperature range of $25^{\circ} \mathrm{C}-32^{\circ} \mathrm{C}$ and relative humidity of $50 \%-95 \%$. The three identical buckets were weighed and filled with sand to the $25 \mathrm{~cm}$ mark from the bottom of each bucket, and a wire mesh placed on top of this sand layer. The remaining top $25 \mathrm{~cm}$ layer in each bucket was then filled with sand amended with 0 (Control-no hydrogel), $0.2 \%$ and $0.4 \%$ hydrogel and labeled accordingly. Using a water sprayer (Trigger sprayer, capacity 1.5 litres-Spray flow: $240 \mathrm{ml} / \mathrm{min}$ ), the buckets were irrigated until full saturation. Any water collecting on the surface was allowed to fully infiltrate. The weights of the fully irrigated buckets were recorded on a Sartorius scale. About $200 \mathrm{~g}$ of Agrostis stolonifera grass seeds were then sown in each bucket containing the various hydrogel treatments (control, $0.2 \%$ and $0.4 \%$ ) by uniformly sprinkling them on the surface of each bucket 
and covering with a thin layer of sand. Water potential meter electrodes were then inserted at three random positions into the top sand layer in each bucket. The water potential was monitored and recorded daily using a potential meter (DMG 900) and whenever it recorded -600 $\mathrm{cm}$ bars, the bucket and its contents were weighed to determine how much water had transpired, and subsequently irrigated until the pressure as recorded by the potential meter dropped to $0 \mathrm{~cm}$ bars. The added water was recorded, and monitoring of the rise in pressure continued for 10 weeks till the grass had fully grown.

After the Agrostis stolonifera grass had fully grown (10 weeks), the buckets were divided into 4 quarters to make four replicates for each bucket. From each quarter, the grass together with the sand mass containing the roots was scooped up to the $25 \mathrm{~cm}$ depth using a small hand shovel. The roots were then washed gently under tap water and then separated from the grass shoots by gently cutting with a pair of scissors. Fresh weight of shoots and roots samples from each quarter was recorded using an electronic Sartorius weighing scale (Model ED $8201-\mathrm{CW})$. The root and shoot samples from each quarter in respective buckets were first sun dried and later oven dried at $65^{\circ} \mathrm{C}$ until a constant weight was attained.

Water use Efficiency was calculated from the ratio of total dry mass (shoot and root) of the grass and the amount of water transpired during the experiment. Transpired water was estimated from the difference in weight of the buckets after complete infiltration was attained at planting time and the weight at subsequent irrigations till the time of harvesting the grass. This measurement was according to [18].

One-way analysis of variance (ANOVA) of SPSS 11.5 software (SPSS Inc., 2002) was used to analyze the effect of hydrogel levels on water uptake by the upper soil layer, water content in the lower sand layer and root and shoot biomass production of Agrostis stolonifera. Differences between means of shoot and root biomass were confirmed by Tukey HSD test, and mean differences were regarded significant at $p \leq 0.05$.

\section{RESULTS}

\subsection{Water Potential and Water Content}

The results of water potential and water content in the lower layer of sand un amended with hydrogel in the three experimental buckets are presented in Figures 1 and 2. The mean water potential in the lower $25 \mathrm{~cm}$ layer un amended with hydrogel was significantly more negative $\left(\mathrm{F}_{(2,9)}=11, p=0.003\right)$ in the $0.4 \%$ hydrogel amendment than in the control implying that less water had infiltrated into this layer (Figure 1). Similarly, water content in the lower $25 \mathrm{~cm}$ sand layer for the control was double that in the $0.4 \%$ hydrogel amendment (Figure 2).

\subsection{Irrigation Frequency and Water Use Efficiency}

The watering/irrigation frequency (Table 1) and water use efficiency (Table 2) of the grass lawn show that the $0.4 \%$ hydrogel amendment required watering only once during the 69 days of growth compared to the control that was irrigated three times in the same period. Less water (9 litres) was applied in the $0.4 \%$ hydrogel amended soil and produced more grass biomass (both shoot and root than the control which was irrigated three times (Table 1) with more water (Table 2) and produced less biomass (Figure 3).

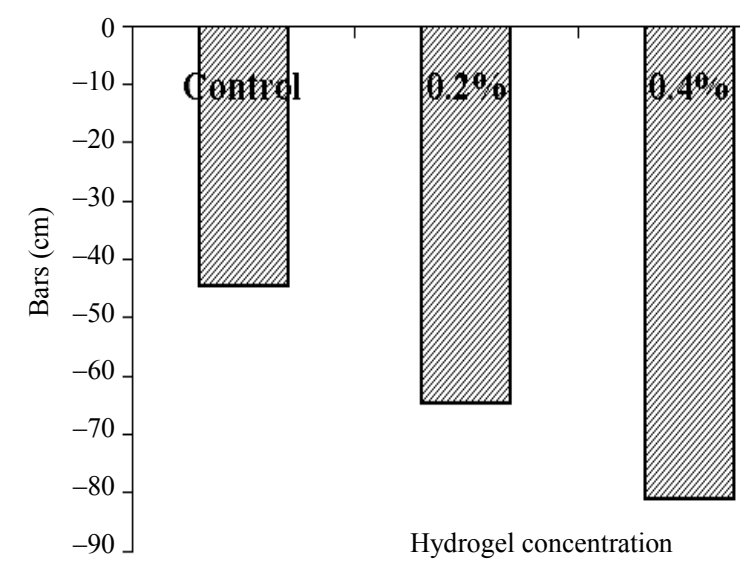

Figure 1. Water potential in the lower un amended $25 \mathrm{~cm}$ depth of sand immediately after harvesting the grass in the buckets.

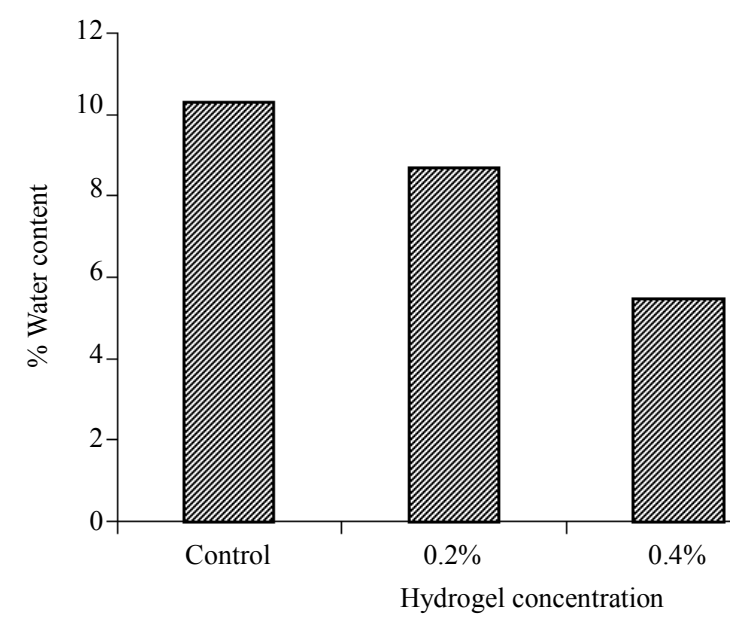

Figure 2. Water content in the lower unamended $25 \mathrm{~cm}$ layer of sand in the three buckets with top $25 \mathrm{~cm}$ sand layer amended at $0 \%, 0.2 \%$ and $0.4 \%$ hydrogel grown with Agrostis stolonifera grass. 
Table 1. Frequency of irrigation, weight of bucket for the various treatments at planting till harvesting of the Agrostis stolonifera grass and estimated transpired water during 69 days of growth. Subsequent irrigations in each treatment were initiated after attainment of $-600 \mathrm{~cm}$ Bars measured by the Potential meter.

\begin{tabular}{lccc}
\hline \multirow{2}{*}{ Point of measurement } & \multicolumn{3}{c}{ Bucket weight (kg) } \\
\cline { 2 - 4 } & Control & $\mathbf{0 . 2 \%}$ hydrogel & $\mathbf{0 . 4 \%}$ hydrogel \\
\hline Before $1^{\text {st }}$ irrigation & 85.4 & 86.2 & 85.8 \\
After $1^{\text {st }}$ irrigation & 91.4 & 95.2 & 94.8 \\
Before $2^{\text {nd }}$ irrigation & 85.9 & 87.1 & - \\
After $2^{\text {nd }}$ irrigation & 94.9 & 96.1 & - \\
Before $3^{\text {rd }}$ irrigation & 87.9 & - & - \\
After $3^{\text {rd }}$ irrigation & 96.9 & - & 94.2 \\
At harvest of the grass & 95.1 & 95.8 & 8.4 \\
Transpired water (Litres) & 24.0 & 18.0 & - \\
\hline
\end{tabular}

Table 2. Amount of water used, shoot and root biomass produced and calculated water use efficiency of Agrostis stolonifera grass in sand soil amended with hydrogel.

\begin{tabular}{cccc}
\hline Treatment & Water used in 69 days $(\mathrm{L})$ & Shoot and root biomass $(\mathrm{g})$ & Water Use efficiency $(\mathrm{g} / \mathrm{L})$ \\
\hline Control & 24 & 37.8 & 1.56 \\
$0.2 \%$ hydrogel & 18 & 49.5 & 2.75 \\
$0.4 \%$ hydrogel & 8.4 & 125.7 & 13.7 \\
\hline
\end{tabular}

\subsection{Effect of Hydrogel Amendment on Grass Shoot and Root Biomass Production}

Hydrogel application at $0.4 \%$ level significantly increased the shoot $\left(\mathrm{F}_{(2,9)}=37.0, p<0.001\right)$ and root biomass $\left(\mathrm{F}_{(2,9)}=24.3, p<0.001\right)$ of the grass by 4 and 2.2 times respectively compared to the control (Figure 3 ). No significant increase in both root $(p=0.482)$ and shoot biomass $(p=0.695)$ was observed in the $0.2 \%$ hydrogel amendment compared to the control. The hydrogel further resulted in growth of a thick root network (Figure 4).

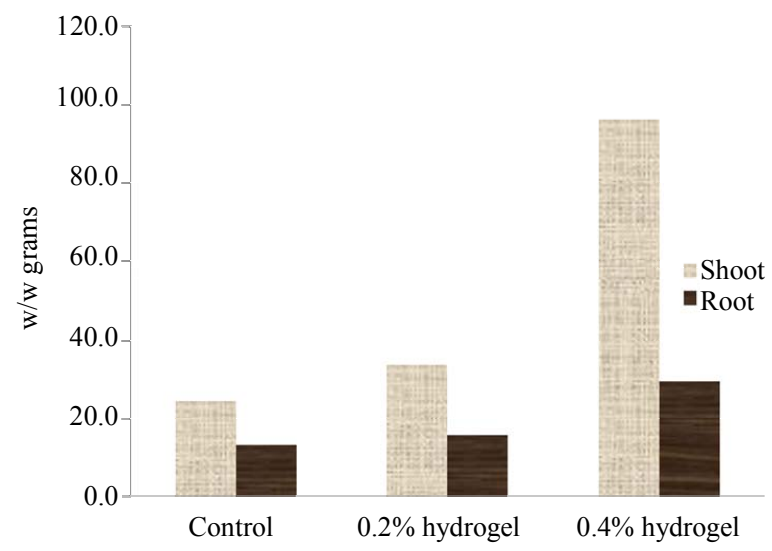

Figure 3. Effect of hydrogel amendment on root and shoot biomass of Agrostis stolonifera grown in sandy soil.

\section{DISCUSSION}

In this study the water use efficiency of the Agrostis stolonifera grass increased by about 8 times compared to the control (Figure 3). The grass grew for 69 days and depended on the 9 litres that was applied at the start of the experiment unlike the control and $0.2 \%$ hydrogel amended soil that were irrigated more than once with 24 and 18 litres of water respectively during the same period (Table 1). The ability of the hydrogel to retain water and release it slowly could be the reason for improved water use efficiency. As shown in Fiugre 4 root aggregation of the grass around fragments of the gel avails water to the roots for a long time thereby contributing to adequate water needs for photosynthesis. These findings are consistent with those of [3] who observed that application of superabsorbent polymer at the rate of $0.6 \%$ in loamy-sandy soil and $0.2 \%$ in sandy clay loam resulted in the highest aerial and root biomass for corn. At these polymer rates $(0.6 \%$ in the loamy sand and $0.2 \%$ in the sandy clay loam), the amounts of aerial and root biomass for corn were 2.3 and 2.0 times greater than those of the control in loamy-sand and 1.6 and 1.7 times that of the untreated sandy clay loam soil, respectively. A greater water use efficiency and dry matter production following application of polymers in the growth media has been reported by [19]. It is common knowledge that water stress is one of the fundamental constraints to productive use of land in the arid and semi-arid areas that perennially 


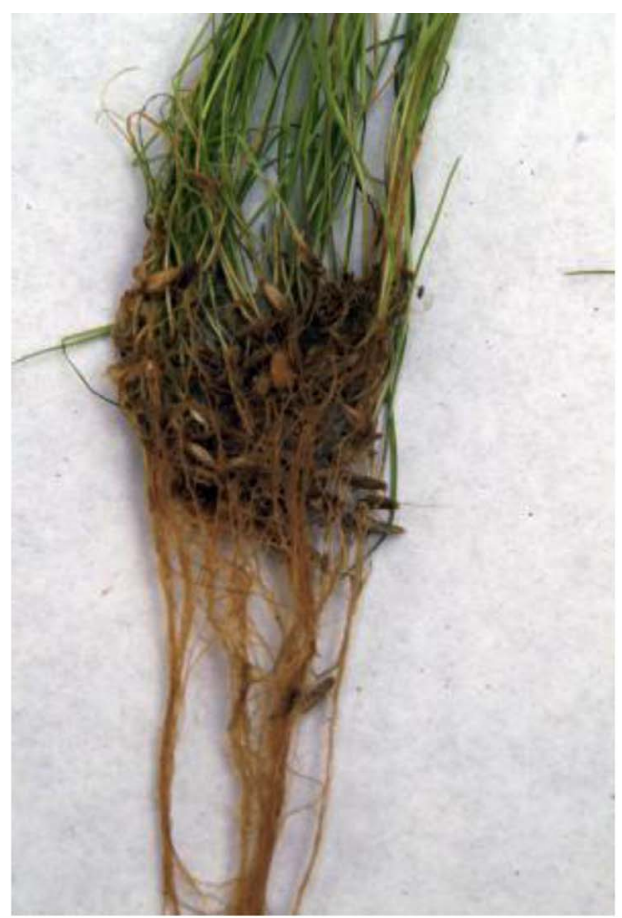

Control

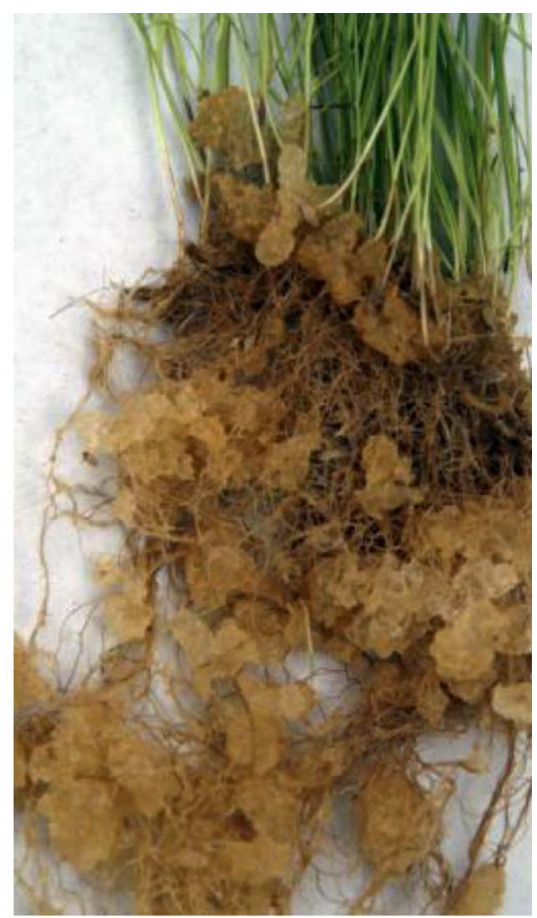

$0.4 \%$ Hydrogel

Figure 4. Root biomass development of Agrostis stolonifera in both the control and $0.4 \%$ hydrogel amended soil.

experience low rainfall. Plant growth is impaired by little or insufficient soil moisture [20]. According to [21] one of the major economic consequences of insufficient water in agricultural systems is yield reduction. Decreased photosynthesis reduces biomass production and results in decreased yields [21-26]. In addition, droughtstress reduces carbon dioxide assimilation, stomatal conductance and transpiration [21-26]. The above was reversed in this study due to adequate supply of water by the gel to the grass roots especially in the $0.4 \%$ hydrogel amendment.

\subsection{Effect of Hydrogel Amendment on Irrigation Frequency, Root Biomass and Water Use Efficiency of Agrostis Stolonifera}

Amendment with $0.4 \%$ hydrogel limited irrigation to only once up to the time of harvesting the Agrostis stolonifera grass (Table 1), implying that enough water was retained by the hydrogel and was available for growth of the grass over the 69 days growth period. Elsewhere, studies have shown that SAP amendments can reduce soil penetration resistance [27], increase soilwater holding capacity $[6,10]$ and soil aggregation while aiding the protection of soil organic matter [28,29]. Studies by [30] showed that hydrophilic polymer addition reduced irrigation frequencies without affecting the growth of Photiniafraseri. Reduced water needs when growing ornamental plants were also reported by $[13$, 31]. According to Sharma [32], plants growing in hydrogel-amended soil have more water available (reflected in higher stomatal conductance and higher leaf water potential) for longer period of time than control plants thus the frequency of irrigation may be reduced. Increase in plant growth may also be due to increased nutrient retention in hydrogel-amended substrate [33].

The $0.4 \%$ hydrogel amendment led to the development of a dense root network (Figure 4) forming some kind of root aggregation with gel fragments that soaked the roots. Root aggregation allows good contact of roots with the moisture source in the polymer and plays a major part in improving water use efficiency of polymer-treated growing systems. Root dipping with polymer gels increases survival of transplants in drying soil [6,34], and inevitably leads to good shoot development as a result of adequate nutrient extraction. It is probable that root dipping and root aggregation around fragments of the gel have similar beneficial effects as both allow better water use efficiency through increased root contact with a source of water that is available to plants.

\subsection{Implications in View of Plantation Forestry}

The implication of this study as far as plantation for- 
estry is concerned is that even a thin soil layer containing a small amount of dry SAP can be able to pick up virtually all rain falling down whereby enough water will be retained and aid tree seedlings establishment in arid areas. In Uganda, the first ever hydrogel application for afforestation of degraded lands in Africa was conducted in four sites namely Nakasongola, Kiruhura, Mpigi and Mubende. Hydrogel was applied at a level of 20 and $40 \mathrm{~g}$ per planting hole, as well as a control. A comparison of the survival of $E$. grandis across the four sites showed significantly higher survival in the hydrogel amended plots than the control in three sites. Data from field experiments in Uganda also indicate that SAP amendments (either 40 or $20 \mathrm{~g}$ per plant hole) significantly improved the growth and above ground biomass of nine tree species (Eucalyptus grandis, Pinus caribaea, Grevillea robusta, Eucalyptus camaldulensis, Maesopsis eminii, Terminalia superba, Araucaria cunninghamii, Azadirachta indica and Melia volkensii) planted in four sites compared to the control (Orikiriza pers. comm. 2011).

Elsewhere in China, The most comprehensive field experiments using hydrogels have been conducted by [35] in the eroded areas of the drainage basin of the upper Jangtze River in Yunnan, which are barren hillsides, heavily washed out by monsoon rains. Their studies showed that the survival of trees was dependent on the time span after planting and that almost $70 \%$ of the trees growing on soils with the highest hydrogel amendment survived after 19 months, whereas more than $80 \%$ of the trees growing on the control soil died during that time. The prolongation of survival of various plants (trees and crops) in higher hydrogel amendment compared to control has been reported by some other authors [6,10,19].

The results have shown that the $0.4 \%$ hydrogel amendment is effective in retaining water in the upper sand layer in the buckets compared to either the $0.2 \%$ or control. Irrigation frequency was reduced in the $0.4 \%$ hydrogel leading to significant amounts of water saved compared to the control. More biomass production of Agrostis stolonifera was achieved with less water in the $0.4 \%$ hydrogel amendment, implying a high water use efficiency of about 8 fold that of the control. This study was conducted under controlled conditions, limited to bucket sizes; and as such the outcomes under field conditions may be completely different. It is recommended that field applications in Uganda's desert like areas be conducted to explore the potential of hydrogels under field conditions.

\section{ACKNOWLEDGEMENTS}

The financial and in-kind support provided for this study is gratefully acknowledged. Specifically, the support from KAAD (Katholischer
Akademicher Auslander Dienst) in Bonn (Germany) and the BASF-SE Chemical Company in Ludwigshafen, (Germany) is highly appreciated.

\section{REFERENCES}

[1] Abd El-Rahim, H.A. (2006) Characterisiation and possible agricultural application of polyacrylamide/sodium alginate crosslinked hydrogels prepared by ionizing radiation. Journal of Applied Polymer Science, 101, 35723580. doi:10.1002/app.22487

[2] Huttermann, A., Orikiriza, L.J.B. and Agaba, H. (2009) Application of superabsorbent polymers for improving the ecological chemistry of degraded or polluted lands. Clean-Soil, Air, Water, 37, 517-526. doi:10.1002/clen.200900048

[3] Dorajji, S.S., Golchin A. and Ahmadi, S. (2010) The effects of hydrophilic polymer and soil salinity on corn growth in sandy and loamy soils. Clean-Soil, Air, Water, 38, 584-591.

[4] Kramer, P.J. and Boyer, J.S. (1995) Water relations of plants and soils. Academic Press, London.

[5] Bhardwaj, A.K., Shainberg, I., Goldstein, D., Warrington, D.N. and Levy, G.J. (2007) Water retention and hydraulic conductivity of cross-linked polyacrylamides in sandy soils. Soil Science Society of America, 71, 406-412. doi:10.2136/sssaj2006.0138

[6] Huttermann A., Zommorodi, M. and Reise, K. (1999) Addition of hydrogels to soil for prolonging the survival of pinus halepensis seedlings subjected to drought. Soil \& Tillage Research, 50, 295-304. doi:10.1016/S0167-1987(99)00023-9

[7] Helalia, A.M. and Letey, J. (1989) Effects of different polymers on seedling emergence, aggregate stability and crust hardness. Soil Science, 148, 199-203. doi:10.1097/00010694-198909000-00007

[8] Teyel, M.Y. and El-Hady, O.A. (1981) Super gel as a soil conditioner. Acta Horticulture, 119, 247-256.

[9] Jobin P., Caron J., Bernier, P.Y. and Dansereau B. (2004) Impact of twohydrophilic acrylic-based polymers on the physical properties of three substrates and the growth of Petunia hybrida "Brilliant Pink". Journal of the American Society for Horticultural Science, 129, 449-457.

[10] Agaba, H., Orikiriza, L.J.B., Esegu, J.F.O., Obua, J., Kabasa, J.D, and Huttermann, A. (2010) Effects of hydrogel amendment to different soils on plant available water and survival of trees under drought conditions. Clean-Soil, Air, Water, 38, 328-335. doi:10.1002/clen.200900245

[11] Fiscus, E.L., Wullschleger, S.D. and Duke, H.R. (1984) Integrated Stomatal opening as indicator of water stress in zea mays. Crop Science, 24, 245-249. doi:10.2135/cropsci1984.0011183X002400020009x

[12] Fiscus, E.L., Mahbub-Ul Alam, A.N.M. and Hirasawa, T. (1991) Fractional integrated stomatal opening to control water stress in the field. Crop Science, 31, 1001-1008. doi:10.2135/cropsci1991.0011183X003100040032x

[13] Taylor, K.C. and Halfacre, R.G. (1986) The effect of hydrophilic polymer on media water retention and nutrient availability to Ligustrum lucidum. Horticultural Sci- 
ence, 21, 1159-1161.

[14] Bai, W., Zhang, H., Liu, B., Wu, Y. and Song, J. (2010) Effects of super-absorbent polymers on the physical and chemical properties of soil following different wetting and drying cycles. Soil Use and Management, 26, 253260. doi:10.1111/j.1475-2743.2010.00271.x

[15] Wallace, J.S. (1991) The measurement and modelling of evaporation from semiarid land. In: Sivakumar, M.V.K., Wallace, J.S., Renard, C. and Giroux, C., Eds., Soil Water Balance in the Sudano-Sahelian Zone. Proceedings of Niamey Workshop, IAHS Publication No. 199, 131-148

[16] Wallace, J.S. (1996) The water balance of mixed treecrop systems. In: Ong, C.K. and Huxley, P., Eds., TreeCrop Interactions: A Physiological Approach, CAB International, Wallingford.

[17] Huttermann, A., Reise, K., Zommorodi, M. and Wang, S. (1997) The use of hydogels for afforestation of difficult stands: Water and salt stress, in semi-arid regions. In: $\mathrm{H}$. Zhou and H. Weisgerber, Eds., Afforestation in Semi-Arid Regions, Datong.

[18] Graciano, C., Guiamet, J.J. and Goya, J.F. (2005) Impact of nitrogen and phosphorus fertilization on drought responses in Eucalyptus grandis seedlings. Forest Ecology and Management, 212, 40-49. doi:10.1016/j.foreco.2005.02.057

[19] Woodhouse, J. and Johnson, M.S. (1991) Effect of superabsorbent polymers on survival and growth of crop seedlings. Agricultural Water Management, 20, 63-70. doi:10.1016/0378-3774(91)90035-H

[20] Ciais, P.H., Reichstein, M., Viovy, N., Granier, A., Allard, V., et al. (2005) Europe-wide reduction in primary productivity caused by the heat and drought in 2003. Nature, 437, 529-533. doi:10.1038/nature03972

[21] Gomez-Cadenas, A., Tadeo, F.R., Talon, M. and PrimoMillo, E. (1996) Leaf abscission induced by ethylene in water stressed intact seedling of Citrus reshni Hort exTan requires previous abscisic acid accumulation in roots. Plant Physiology, 112, 401-408.

[22] Sinclair, T.R. and Allen, L.H.Jr. (1982) Carbon dioxide and water vapour exchange of leaves on field-grown citrus trees. Journal of Experimental Botany, 33, 11661175. doi:10.1093/jxb/33.6.1166

[23] Syvertsen, J.P., Lloyd, J. and Kriedemann, P.E. (1988) Salinity and drought stress effects on ion concentration, water relations and photosynthetic characteristics of orchard citrus. Australian Journal of Agricultural Research, 39, 619-627. doi:10.1071/AR9880619

[24] Arbona, V., Iglesias, D.J., Jacas, J., Primo-Millo, E. and
Talon, M. (2005) Hydrogel substrate amendment alleviates drought effects on young citrus plants. Plant Soil, 270, 73-82. doi:10.1007/s11104-004-1160-0

[25] Perez-Perez, J.G., Syvertsen, J.P., Botia, P. and Garcia-Sanchez, F. (2007) Leaf water relations and net gas exchange responses of salinized Carrizo citrange seedlings during drought stress and recovery. Annals of Botany, 100, 335-345. doi:10.1093/aob/mcm113

[26] Garcia-Sanchez, F., Syvertsen, J.P., Gimeno, V., Botia, P. and Perez-Perez, J.G. (2007) Responses to flooding and drought stress by two citrus rootstocks seedlings with different water-use efficiency. Physiology and Plantarum, 130, 532-542. doi:10.1111/j.1399-3054.2007.00925.x

[27] Busscher, W.J., Bjorneberg, D.L. and Sojka, R.E. (2009) Field application of PAM as an amendment in deep-tilled US southeastern coastal plain soils. Soil \& Tillage Research, 104, 215-220. doi:10.1016/j.still.2009.02.009

[28] Goebel, M.O., Bachmann, J., Woche, S.K. and Fischer, W.R. (2005) Soil wettability, aggregate stability, and the decomposition of soil organic matter. Geoderma, 128, 80-93. doi:10.1016/i.geoderma.2004.12.016

[29] John, B., Yamashita, T., Ludwig, B. and Flessa, H. (2005) Storage of organic carbon in aggregate and density fractions of silty soils under different types of land use. $\mathrm{Ge}$ oderma, 128, 63-79. doi:10.1016/j.geoderma.2004.12.013

[30] Dehgan, B., Yeager T.H. and Almira, F.C. (1994) Podocarpus growth response to a hydrophilic polymer-amended medium. Horticultural Science, 29, 641-644.

[31] Flannery, R.L. and Busscher, W.J. (1982) Use of a synthetic polymer in potting soil to improve water holding capacity. Soil Science and Plant Analysis, 13, 103-111. doi: 10.1080/00103628209367249

[32] Sharma, J. (2004) Establishment of perennials in hydrophilic polymer amended soil. SNA Research Conference, 42, 30-532.

[33] Orikiriza, J.L.B., Agaba, H., Tweheyo, M., Eilu G., Kabasa, J.D. and Hutterman, A. (2009) Amending soils with hydrogels increases the biomass of nine tree species under non-water stress conditions. Clean-Soil, Air, Water, 37, 615-620. doi:10.1002/clen.200900128

[34] Hamilton, J.L. and Lowe, R.H. (1982) Use of a water absorbent polymer in tobacco seedling production and transplanting. Tobacco Science, 26, 17-20.

[35] Ma, H.C., and Nelles-Schwelm, E. (2004) Application of hydrogels for vegetation recovery in dry-Hot Valley of Yangtze. Yunnan Academy of Sciences, Yunnan. 